\title{
PRODUKSI KERAJINAN DADAK MERAK TERHADAP POPULASI JENIS BURUNG MERAK HIJAU (Pavo Muticus) di KABUPATEN PONOROGO
}

\author{
(Production of peacock craft against population of the type green peacock (Pavo muticus) in \\ Ponorogo Regency)
}

\author{
Hendi Vista Asy'ari, Ramli Ramadhan*, Mochamad Chanan \\ Program Studi Kehutanan, Universitas Muhammadiyah Malang, Malang, Indonesia 65144 \\ *email: ramliramadhan@umm.ac.id
}

\begin{abstract}
The preservation of Reog culture in Ponorogo Regency was very dependent on the availability of raw materials for the Green Peacock. However the population growth of Merak Hijau is decreasing, on the other hand Ponorogo Regency needs to preserve the existence of Reog art. So this study aims to determine the relationship of peacock breast growth growth to the level of population of the type of green peacock (Pavo muticus) ex situ in Ponorogo Regency. Analysis of the relationship between population growth and growth of peacock breast production using the Spearman rank correlation method to determine the level of significance. The next step was analyzing the business opportunity using $B$ / C ratio to find out the prospect of peacock peacock business. The results showed that the production of high peacock breast did not correlate with the increase in green peacock population. This was due to the lack of information and the lack of assistance to breeders of ex-situ captive breeding methods so that craftsmen choose to substitute using blue peacock from imported materials. The $B$ / $C$ ratio value on the green peacock indicates 1.11 and the blue peacock is 1.32 so the peacock peacock handicraft business activity has a decent prospect.
\end{abstract}

Keywords: Green Peacock, Peacock Dadak, Ponorogo

\section{Abstrak}

Pelestarian budaya Reog di Kabupaten Ponorogo sangat bergantung pada kesediaan bahan baku burung Merak Hijau. Namun saat ini pertumbuhan populasi Merak Hijau semakin menurun, disisi lain Kabupaten Ponorogo perlu melestarikan keberadaan kesenian Reog. Sehingga penelitian ini bertujuan untuk mengetahui hubungan pertumbuhan produksi dadak merak terhadap tingkat populasi jenis merak hijau (Pavo muticus) secara ex situ di Kabupaten Ponorogo. Analisis hubungan antara pertumbuhan populasi dan pertumbuhan produksi dadak merak menggunakan metode korelasi spearman rank untuk mengetahui tingkat signifikansi. Selanjutnya dilakukan analisis peluang usaha menggunakan B/C ratio untuk mengetahui prospek usaha kerajinan dadak merak. Hasil penelitian menunjukkan bahwa produksi dadak merak yang tinggi tidak berkolerasi terhadap pertambahan populasi merak hijau. Hal ini disebabkan karena minimnya ifnormasi dan kurangnya pendampingan terhadap para penangkar terhadap metode penangkaran secara ex-situ sehingga pengrajin memilih melakukan subtitusi menggunakan merak biru dari bahan impor. Nilai B/C ratio pada dadak merak hijau menunjukkan nilai 1,11 dan dadak merak biru 1,32 sehingga kegiatan usaha kerajinan dadak merak memiliki prospek yang layak.

Kata Kunci: Dadak Merak, Merak Hijau, Ponorogo

\section{PENDAHULUAN}

Budaya kesenian Reog merupakan ikon penting di Kabupaten Ponorogo yang telah berkembang sejak abad 15 dan terus dilestarikan hingga saat ini
(Kurnianto, 2013). Ponorogo sendiri merupakan kota Reog sehingga kesenian tersebut menjadi salah satu penggerak ekonomi dibidang pariwisata. Disisi lain, bahan baku yang 
digunakan dalam setiap penampilan Reog berasal dari satwa jenis burung merak hijau (Pavo muticus Linnaeus, 1766). Mulai penggunaan kepala, bulu, ekor dan sayap dalam pembuatan topeng dadak merak. Pembuatan satu dadak merak biasanya membutuhkan sedikitnya 1000 (seribu) helai bulu merak hijau jantan. Satu ekor merak hijau memiliki sekitar 150 (seratus lima puluh) helai bulu hias sehingga untuk memproduksi satu dadak merak membutuhkan sekitar 9-10 ekor merak hijau jantan (Purwaningsih, 2010). Lebih lanjut, menurut (Hernowo, 2011) pembuatan 1 buah topeng dadak merak membutuhkan sekitar 10-20 ekor pejantan merak hijau. Kebutuhan merak hijau terhadap keberlanjutan kesenian Reog sangat besar karena memiliki nilai budaya yang cukup tinggi dan bulu ekor merak hijau jantan sangat dicari sebagai ornamen dadak merak (Pudyatmoko, 2018). Sehingga mengancam jumlah populasi merak hijau karena jenis burung ini dilindungi dan terancam punah menurut kriteria IUCN dengan tren populasi yang terus menurun di berbagai negara seperti Kamboja, Laos, Indonesia dan China (Sukumal et.al, 2015). Populasi jenis burung ini sendiri tersebar di berbagai tipe habitat seperti savana, hutan pantai, hutan jati (Balen et.al, 2005) sehingga mudah untuk ditemui di alam Status dalam negeri menunjukkan jenis satwa merak hijau dilindungi menurut PP No.7 tahun 1999 dan PermenLHK No.106 tahun 2018 tentang pertumbuhan dan satwa dilindungi. Penyebab menurunnya populasi jenis ini di alam ialah karena rusaknya habitat, perburuan liar dan penangkapan anak serta pengambilan telur di alam (Hernowo 2011a; Tarigan, 2001).

Data BPS di tahun 2013 di Kabupaten Ponorogo menunjukkan justru terjadi peningkatan jumlah pengrajin dadak merak dari mulai tahun 2007 berjumlah 16 pengrajin hingga tahun 2013 berjumlah 16 pengrajin (Naning \& Titi, 2017). Angka tersebut diduga akan terus naik karena kesenian Reog merupakan satu-satunya promosi budaya yang sangat berpengaruh, selain itu tentu berkaitan dengan keberlanjutan budaya yang harus dilestarikan. Fakta diatas memunculkan perdebatan dikalangan penggiat konservasi yang menginginkan perlindungan merak hijau dan disisi lain para pengrajin membutuhkan bahan baku dari merak hijau untuk membuat dadak merak. Semakin tingginya permintaan bahan baku dan semakin menurunnya jumlah pasokan spesimen merak hijau, menyebabkan para pengrajin mengambil langkah dengan mengalihkan bahan baku ke spesimen merak biru yang diperoleh dengan cara impor dari negara India dan China. Sehingga hal ini dapat menyebabkan jumlah penangkar yang semakin menurun karena para pengrajin memilih jalur impor. Namun demikian tidak mudah membuat penangkaran burung merak karena beberapa gangguan tidak seperti di alam / in-situ (Istijabatul et al., 2014). Dari fakta diatas, maka penelitian ini ingin mengisi gap terhadap studi mengenai pertumbuhan produksi dadak merak dengan jumlah 
populasi merak hijau secara $e x$-situ atau penangkaran di Kabupaten Ponorogo. Penelitian sebelumnya berfokus pada jumlah populasi di habitat aslinya / insitu (Takandjandi \& Reny, 2010; Pudyatmoko, 2019) dan model penangkaran guna mendukung revitalisasi kesenian Reog (Istijabtul, et al., 2014). Sehingga tujuan penelitian ialah mengetahui hubungan antara pertumbuhan populasi ex-situ dengan pertumbuhan produksi dadak merak serta prospek usahanya hingga saat ini.

\section{METODE PENELITIAN}

\section{Lokasi Penelitian}

Lokasi penelitian berada di 9 desa tepatnya ada 17 titik lokasi yang telah dipilih (purposive sampling) karena terdapat pusat pengrajin topeng dadak merak. Penelitian dilakukan pada rentang bulan Januari hingga Maret 2020.

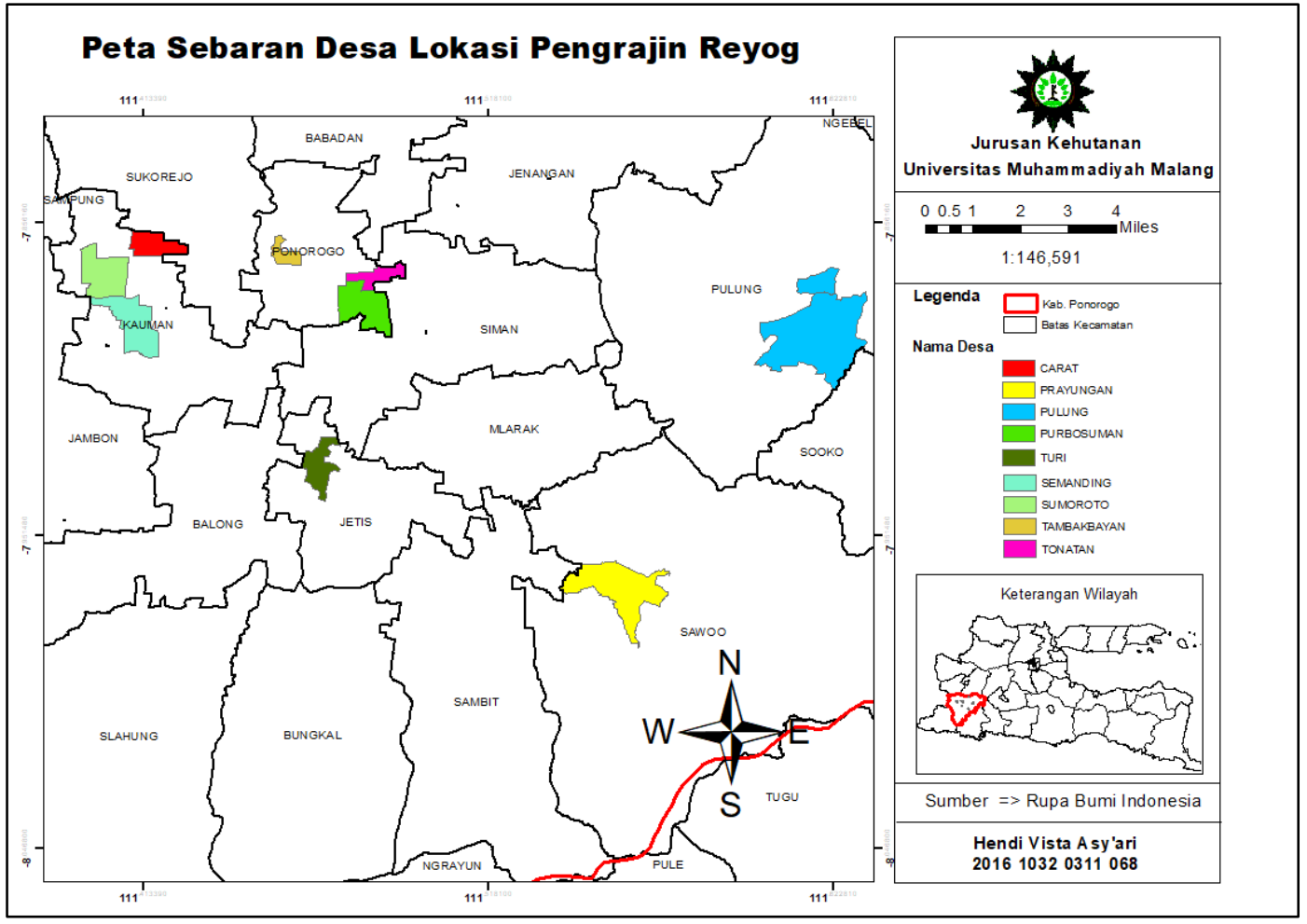

Bahan yang digunakan dalam penelitian ini meliputi 17 orang pengrajin, penangkar merak hijau yang tersebar di wilayah Kab. Ponorogo, Balai Besar Konservasi Sumber Daya Alam (BKSDA) wilayah I Madiun, Dinas Perindustrian, Perdagangan, Koperasi, dan UMKM Ponorogo.

Tahapan Penelitian.

Data yang diperoleh dari hasil wawancara menggunakan kuisioner maupun wawancara secara mendalam diseleksi dan diolah menggunakan metode deskriptif statistik untuk mengetahui data tentang pertumbuhan bahan baku dengan pertumbuhan populasi merak hijau di Ponorogo. Selanjutnya data dianalisis menggunakan uji korelasi rank spearman. Terhadap prospek usaha dihitung menggunakan metode Benefit Cost Ratio (B/C Ratio). Kriteria kelayakan dinilai layak dijalankan apabila $\mathrm{B} / \mathrm{C}$ ratio $>1$, apabila $<1$ tidak 
layak dijalankan sedang $\mathrm{B} / \mathrm{C}$ Ratio $=1$ maka usaha tidak menguntungkan maupun merugikan.

HASIL DAN PEMBAHASAN Pertumbuhan Produk Dadak Merak dan Prospek Usaha Dadak Merak

Jumlah pengrajin di Kab. Ponorogo dari tahun 2015 hingga 2019 mengalami peningkatan walaupun tidak terlau signifikan. Pada tahun 2019 jumlah pengrajin dadak merak berjumlah 17 orang, sedangkan permintaan produk dadak merak mengalami kenaikan pada tahun 2019 mencapai 228 buah (gambar 2).

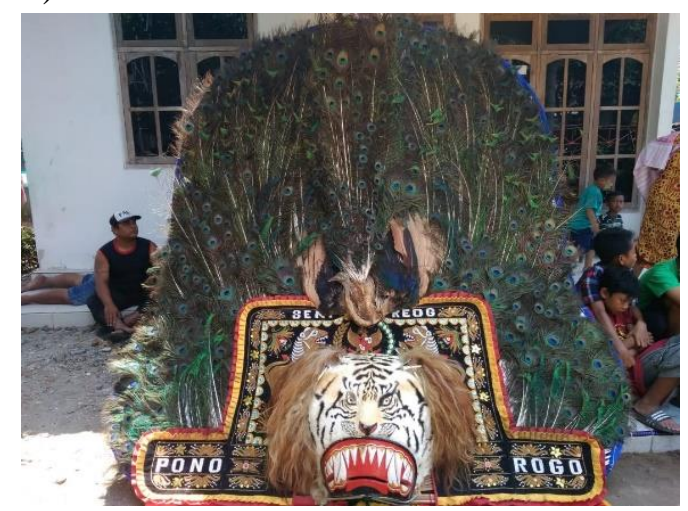

\section{Gambar 1. Dadak Merak Hijau}

Permintaan terhadap produk dadak merak yang tinggi karena beberapa faktor yaitu banyaknya event yang diselenggarakan oleh Pemkab Ponorogo seperti Festival Reog Nasional (FRN) yang mengundang peserta dari lokal maupun mancanegara, sampai dengan acara yang mengundang masyarakat seperti Grebeg Suro 1 Muharram, hajatan dan seterusnya. Satu unit dadak merak sendiri dihargai kisaran antara 20 sampai 25 juta (Naning dan Titi, 2017). Selain itu, masih banyaknya paguyuban reog juga menjadi faktor pertumbuhan terhadap produk dadak merak. Tidak hanya mengincar pangsa di dalam wilayah Ponorogo saja, namun persebaran produk menurut keterangan dari responden tersebar di berbagai daerah dari mulai Jawa, Kalimantan, hingga Papua sedangkan pangsa internasional negara yang tertarik dari Malaysia, Korea Selatan, Belanda, hingga Amerika Serikat. Hal tersebut menunjukkan bahwa pertumbuhan usaha dadak merak selain melestarikan budaya juga menjanjikan secara ekonomi.

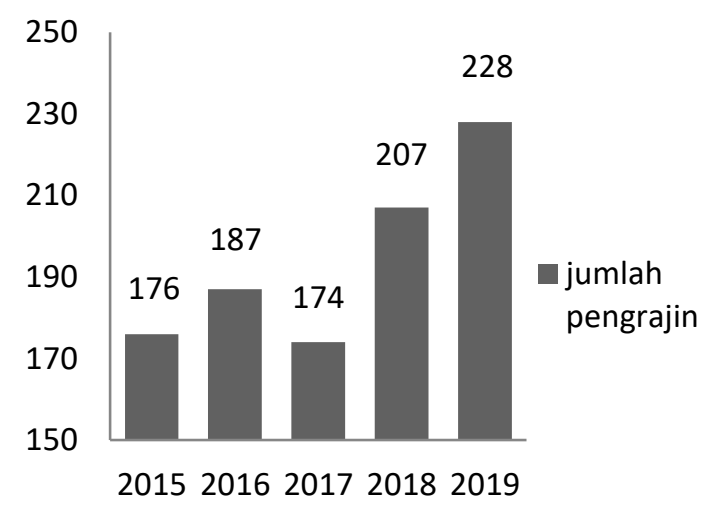

Gambar 2. Jumlah Pengrajin Dadak Merak

Hasil analisis mengenai prospek usaha kerajinan dadak merak menunjukkan bahwa usaha dadak merak layak untuk dijalankan. Menggunakan metode $\mathrm{B} / \mathrm{C}$ ratio menunjukkan bahwa sekali produksi dadak merak hijau membutuhkan biaya produksi sebesar Rp. 11.332.500, sedangkan dengan bahan baku merak biru membutuhkan biaya produksi sebesar Rp 13.082.500. Menurut hasil wawancara, harga jual dadak merak hijau di pasaran seharga Rp. 18.500.000 hingga Rp. 20.000.000, sedangkan untuk dadak merak biru dihargai kisaran Rp. 14.000.000 hingga 15.000.000 tergantung dengan hasil garapan dan variasi. Dari sini menunjukkan bahwa nilai $\mathrm{B} / \mathrm{C}$ ratio 
untuk dadak merak hijau sebesar 1.11 sedangkan dadak merak biru sebesar 1.32. Hasil tersebut menunjukkan bahwa usaha kerajinan dadak merak layak dan menguntungkan karena nilai ratio $>1$. Pemenuhan bahan baku dadak merak biru yang diperoleh dari impor justru lebih menguntungkan sehingga banyak pengrajin saat ini yang berpindah menggunakan spesimen dadak merak biru. Selain itu, bulu merak biru memiliki ukuran yang lebih besar sehingga proses pengerjaannya lebih mudah. Namun masih banyak pengrajin yang berpandangan bahwa bahan dasar merak hijau tetap sebagai pilihan utama karena terletak pada nilai sejarah dan sosial yang tidak tergantikan.

\section{Populasi Merak Hijau terhadap} Pertumbuhan Produksi Dadak Merak

Populasi Merak Hijau di Kabupaten Ponorogo sangat tergantung dengan jumlah penangkar. Menurut PP No. 8 tahun 1999 tentang pemanfaatan jenis tumbuhan dan satwa liar, perdagangan merak hijau wajib melalui hasil penangkaran generasi kedua dan berikutnya sehingga status satwa burung merak hijau menjadi tidak dilindungi. Saat ini di pulau jawa jumlah burung merak hijau kurang dari 800 ekor akibat rusaknya habitat dan adanya perburuan liar. Selain itu faktor cuaca seperti suhu dan kelembapan menjadi kunci karena berpengaruh terhadap telur yang sedang dierami oleh indukan, sehingga metode penangkaran memerlukan suhu dan kelembapan yang sesuai agar mampu bertelur. Persyaratan pembuatan penangkaran merak hijau tidak mudah karena perlu mempertimbangkan aspek ekologi, aksesibilitas, hingga konstruksi kandang yang semirip mungkin dengan habitat alaminya (Istijabtul, et al., 2014). Di Kabupaten Ponorogo sendiri memiliki 4 penangkar dengan status 2 (dua) sudah memiliki izin dan 2 (dua) sisanya sedang dalam proses pengajuan. Hasil penelitian menunjukkan bahwa pertumbuhan populasi merak hijau meningkat pesat di tahun 2019 dengan jumlah 36 ekor dari yang sebelumnya pada tahun 2018 berjumlah 22 ekor (gambar 3). Namun hal tersebut belum mampu menutupi permintaan dari para pengrajin dadak merak yang produksinya mencapai 228 buah di tahun 2019.

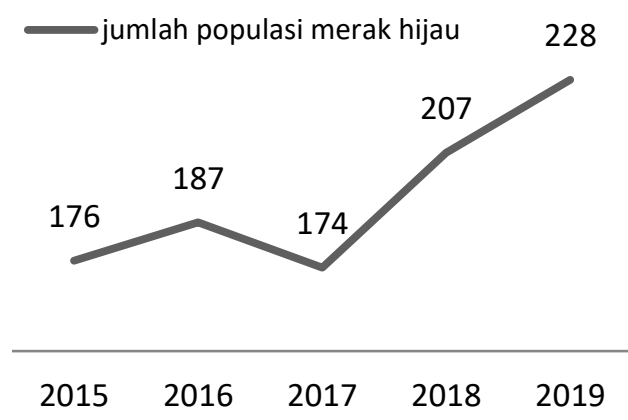

Berdasar hasil analisis uji korelasi spearman rank diketahui bahwa pertumbuhan produksi dadak merak hijau tidak berkorelasi atau tidak berpengaruh signifikan dengan laju pertumbuhan populasi merak merak hijau dengan nilai sebesar 0,42 atau lebih lebih besar dari 0,5. Hal tersebut menunjukkan bahwa potensi populasi dadak merak hijau di alam semakin terancam karena kebutuhan terhadap keberlanjutan budaya di Kabupaten Ponorogo. Namun disisi lain, para 
pengrajin saat ini mulai merubah pakem yang sebelumnya menggunakan spesimen merak hijau beralih ke spesimen merak biru dengan cara mengimpor bahan baku bulu merak biru. Perubahan pakem terlihat dari segi warna dimana bulu merak hijau memiliki warna khas merah keemasan sedangkan bulu merak biru berwarna hijau kekuningan.

Pemerintah Kabupaten Ponorogo dan BKSDA memiliki peran sangat penting terkait kebijakan penangkaran. Salah satu penyebab populasi terus menurun karena minimnya informasi tentang metode penangkaran yang baik sehingga para penangkar enggan membuatnya. Belum adanya studi kelayakan habitat ex-situ membuat sulitnya menghasilkan telur karena banyak terjadi kematian secara mendadak akibat tidak paham cara menangkar merak hijau. Sehingga diharapkan pemerintah memberi pendampingan secara intensif terhadap para penangkar dan masyarakat yang ingin memperoleh ijin menangkar, sehingga populasi merak hijau terus meningkat dari waktu ke waktu.

\section{KESIMPULAN}

Produksi dadak merak diperkirakan akan terus meingkat melihat tren pertumbuhannya sampai tahun 2019, namun populasi merak hijau terutama di habitat ex-situ mengalami stagnanisasi akibat minimnya informasi kepada penangkar terkait perijinan dan metode penangkaran yang tepat. Hasil analisis uji korelasi Spearman Rank menunjukkan nilai 0,42 bahwa tidak adanya korelasi antara pertumbuhan produksi dengan populasi merak hijau. Mmetode penangkaran yang sulit membuat para penangkar tidak dapat menetaskan telur merak hijau karena membutuhkan persyaratan yang tidak sedikit sehingga membutuhkan pendampingan, modal, hingga aspek ekologi merak hijau itu sendiri. Sehingga untuk mengatasi kelangkaan demi memenuhi kebutuhan produksi saat ini para pengrajin merubah pakem dengan menggunakan spesimen bulu merak biru yang didatangkan dari impor. Menurut hasil analisis $\mathrm{B} / \mathrm{C}$ ratio, menggunakan bahan baku merak biru layak untuk dijalankan dengan nilai ratio 1.32. Penelitian ini memberi saran kepada pihak terutama Kabupaten Ponorogo dan BKSDA untuk melakukan pendampingan secara intensif terhadap proses penangkaran dari mulai ijin hingga teknis pembuatan kandang dan pemeliharaan merak hijau di dalam kandang. Karena hanya dengan begitu kelestarian budaya dan kelestarian burung merak hijau dapat terus terjaga.

\section{DAFTAR PUSTAKA}

Balen V, Prawiradilaga DM, Indrawan, M. (1995). The Distribution and Status of Green Paefowl Pavo muticus in Java. Biological Conservation. Vol. 71. 289-297.

Hernowo, J., dkk., (2011). Behavior Ecology of the Javan Green Peafowl (Pavo muticus muticus Linnaeus 1758) in Baluran and Alas Purwo National Park, East Java. HAYATI Journal of Biosciences Vol. 18 No. 4, p 164176. EISSN : 2086-4094. Institut Pertanian Bogor. Bogor. 
Hernowo, JB. (2011). Population Analysis of The Javan Green Peafowl (Pavo muticus Linnaeus 1758) in Baluran and Alas Purwo National Parks, East Java. Biodiversitas-Journal of Biological Diversity. Vol. 12. 99106.

doi:10.13057/biodiv/d120207

Istijabatul, A., Purwanto, S. N., Galing, Y. (2014). Model Pengembangan Kawasan Penangkapan Burung Merak Untuk Mendukung Revitalisasi Kesenian Reyog dan Menunjang Pembangunan Pariwisata Di Kabupaten Ponorogo. Journal of Rural and Develpoment. Vol.V.No.2.129146.

Kurnianto, R. (2013). Sejarah dan Dinamika Seni Reyog Ponorogo. Universitas Muhammadiyah Ponorogo. Ponorogo.

Naning, K. \& Titi, R. (2017). Dinamika Usaha Pengrajin Reog Ponorogo. Jurnal Riset Akuntansi dan Bisnis Airlangga. Vol. 2. No. 1. 149-164.

Purwaningsih, Dyah Ayu, (2010), Faktor-Faktor Penentu Keberhasilan Penangkaran Merak Hijau Jawa (Pavo muticus muticus) di Taman Margasatwa Ragunan dan Taman Burung Taman Mini Indonesia Indah (TMII) Jakarta, Bogor: Institut Pertanian Bogor. Laporan Penelitian.

Pudyatmoko, S. (2019). Habitat dan Interaksi Saptio-Temporal Merak Hijua dengan Sapi dan Herbivora Besar di Taman Nasional Baluran. Jurnal Ilmu Kehutanan Vol. 13. 28-37.

Sukumal, N, McGowan PJK, Savini, T. (2015). Change in Status of Green Peafowl Pavo muticus in Southcentral Vietnam: A Comparison over 15 years. Global Ecology and Conservation. Vol. 2. 1119.doi:10.1016/j.gecco.2014.10 .007

Takandjandji, M \& Reny, S. (2011). Populasi Burung Merak Hijau (Pavo muticus Linnaeus, 1766) Di Ekosistem Savana, Taman Nasional baluran, Jawa Timur. Jurnal Penelitian Hutan dan Konservasi Alam. Vol. 8. No.1. 13-24

Tarigan, N. (2001). Penangkaran Burung Merak. Yogyakarta: Penerbit Kanisius. 